\title{
Sense of alexithymia in patients with anxiety disorders comorbid with recurrent urticaria
}

\author{
This article was published in the following Dove Press journal: \\ Neuropsychiatric Disease and Treatment \\ 21 April 2016 \\ Number of times this article has been viewed
}

\author{
Ewa A Ogłodek' \\ Anna M Szota' \\ Marek J Just ${ }^{2}$ \\ Aleksander Araszkiewicz' \\ Adam R Szromek ${ }^{3}$ \\ 'Department of Psychiatry, Collegium \\ Medicum in Bydgoszcz, Nicolaus \\ Copernicus University in Toruń, \\ Toruń, ${ }^{2}$ Department of General \\ and Endocrine Surgery, Municipal \\ Hospital, Piekary Śląskie, ${ }^{3}$ Department \\ of Organization and Management, \\ Silesian University of Technology, \\ Gliwice, Poland
}

\begin{abstract}
Aim: Alexithymia is associated with limited cognitive processing of emotions by an individual suffering from recurrent urticaria and alexithymia and makes them focus on somatic manifestations of emotional arousal and on poorly controlled compulsive reactions to negative stimulation. Alexithymia is considered to be a personality trait, which, along with other factors, predisposes individuals toward developing somatic diseases. The aim of the study was to assess the measurement of alexithymic features in patients with recurrent urticaria and to assess the types of concurrent anxiety disorders and overall anxiety level.
\end{abstract}

Methods: In order to diagnose clinical anxiety symptoms in patients, the Diagnostic and Statistical Manual of Mental Disorders, Fifth Edition and the Hamilton Anxiety Rating Scale were applied. Alexithymic features were measured by means of a shortened version of the Toronto Alexithymia Scale, characterized by high discrimination power, internal coherence, and reliability.

Results: According to the Toronto Alexithymia Scale results, the greatest contributing factor was "inability to differentiate between feelings and bodily sensations". This was observed in both males and females. Most frequently, the patients were found to suffer from generalized anxiety disorder and social phobia.

Conclusion: Alexithymia may result from the difficulty associated with expressing emotions caused by anxiety disorders. Undergoing treatment for anxiety disorders may contribute to reduced exacerbation of urticaria.

Keywords: alexithymia, anxiety, recurrent urticaria

\section{Introduction}

The alexithymia construct was created by psychiatrist Peter Sifneos. Individuals with alexithymia find it difficult to identify or describe their own emotions, recognize emotional states in others, or distinguish between emotions and bodily sensations. ${ }^{1,2}$ The prevalence of alexithymia in the general population ranges between $10 \%-13 \%$. Males have been reported to manifest alexithymia symptoms more frequently $(12.8 \%-17.0 \%)$ than females $(8.2 \%-10.0 \%) .{ }^{3}$ Individuals with alexithymia attribute the cause of their emotional problems to external events rather than their own inner experience. Significant exacerbation of alexithymia symptoms is reflected in a specific functioning style. ${ }^{4}$ Interpersonal relations of patients with alexithymia are marked with indifference toward others' expectations, coldness, and reserve. ${ }^{5}$ Affected individuals also tend to have limited imagination, primarily with regard to positive events. Images arising from negative emotions are evoked more easily. ${ }^{6}$ Patients with alexithymia are also said to have both poor introspective and overly concrete thinking styles. ${ }^{7}$ As a result, verbal expression of emotions and cognitive reflection of emotional processes are impaired. This is followed by inclination of affected individuals to react to external
Correspondence: Ewa A Ogłodek Department of Psychiatry, Collegium Medicum in Bydgoszcz, Nicolaus Copernicus University in Toruń, 9 CurieSklodowska Street, 85-094 Bydgoszcz, Poland

Tel +48525854260

Fax +48525854266

Email ewa.oglodek@wp.pl
Neuropsychiatric Disease and Treatment 2016:12 995-1004

Dovepress

http://dx.doi.org/1 0.2147/NDT.S94600 (c) (1) (5) 2016 ogłodek et al. This work is published and licensed by Dove Medical Press Limited. The full terms of this license are available at https://www.dovepress.com/terms.php C. hereby accept the Terms. Non-commercial uses of the work are permitted without any further permission from Dove Medical Press Limited, provided the work is properly attributed. For permission for commercial use of this work, please see paragraphs 4.2 and 5 of our Terms (https://www.dovepress.com/terms.php). 
events with unmoderated states of physiological arousal. ${ }^{8}$ Several studies indicate that alexithymia is likely a triggering and/or maintaining factor for numerous somatic diseases, including dermatological conditions, for example, chronic idiopathic urticaria (CIU), and mental disorders. ${ }^{9-11}$ Patients suffering from alexithymia are diagnosed with greater exacerbation of anxious-depressive symptoms. ${ }^{12}$ Other studies have revealed that individuals with alexithymia manifest changes in the activity of the sympathetic nervous system, the immune system, and the brain. ${ }^{13-15}$ Changes in the brain activity of these patients can be seen on functional magnetic resonance imaging. ${ }^{16}$ Emotional information from the right hemisphere is not properly transferred to language regions in the left hemisphere. This may result from a reduced size of the corpus callosum, which is regularly observed in psychiatric patients. One neuropsychological study found that the cause of alexithymia may be related to a disturbance of the right hemisphere, being that it is largely responsible for processing emotions. ${ }^{17}$ Furthermore, another neuropsychological study suggests that alexithymia could be caused by dysfunction in the anterior cingulate cortex. Higher autonomic reactivity is regarded as an adverse disposition that has a significant influence on stress-related mental and somatic disorders. ${ }^{18,19}$

Alexithymia is a risk factor for the development of somatoform disorders in patients who have experienced chronic stress. The skin, being the largest body organ, forms a barrier between the organism and the environment and is constantly exposed to harmful stressors. This is where nerve endings are located, and they transmit information about touch, itch, pain, temperature, and other physical stimuli to the central nervous system. ${ }^{20}$ The relationship between stress, emotions, and regulation of the nervous, immune, and endocrine system activity, as well as its impact on the skin condition, is represented by the neuro-immuno-cutaneous-endocrine model (Figure 1). The model illustrates that stress induces inflammatory activation of the hypothalamic-pituitary-adrenal axis and causes the release of hormones, cytokines, and neurotransmitters. This may result in dermatitis and, for example, recurrence of CIU. The studies available show that the skin lesions that occur in the course of the disease, such as skin rash with wheals and itch, are connected with psychological problems and last at least 6 weeks. ${ }^{21-23}$ The psychological factors may involve unelaborated and suppressed emotions. They may manifest as difficulty describing emotions, for example, expressing anger. Recurrent urticaria concomitant with alexithymia may negatively affect the quality of life and increase anxiety severity. ${ }^{11,24}$

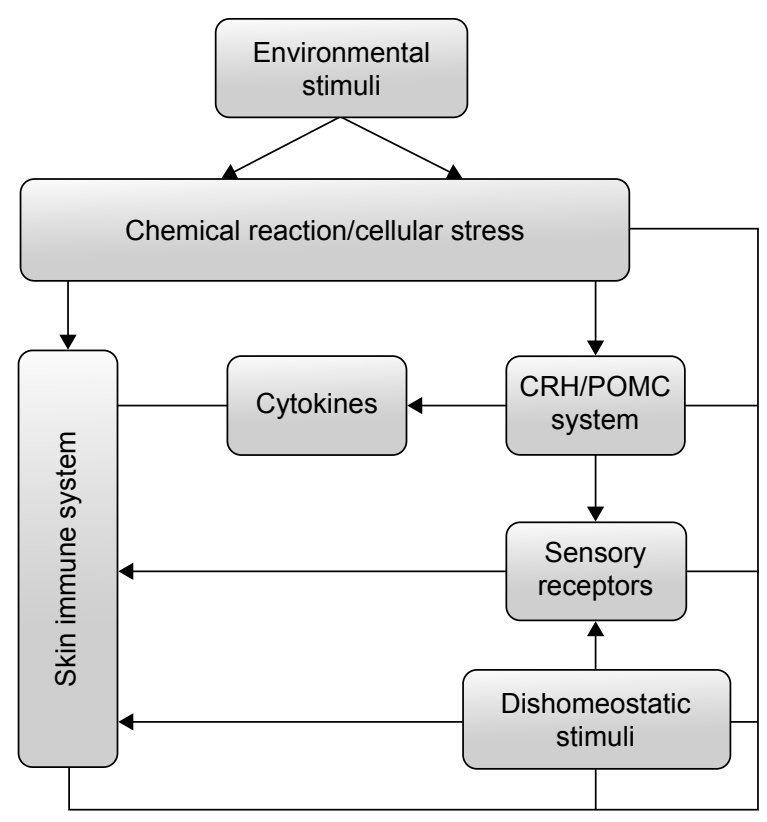

Figure I Cutaneous response to stress (NICE model).

Note: The CRH/POMC system is the integrator and coordinator of the local response to environmental and dyshomeostatic (internal) stimuli.

Abbreviations: NICE, neuro-immuno-cutaneous-endocrine; $\mathrm{CRH}$, corticotropin releasing hormone; POMC, proopiomelanocortin.

The aim of this study was to assess the anxiety level and alexithymia severity in individuals with a history of CIU and anxiety disorders, namely panic disorders (PDs), generalized anxiety disorders (GAD), and social phobia (SF). This assessment allowed identification of groups that were at the highest risk for urticaria recurrence caused by exacerbation of alexithymia.

\section{Patients and methods}

\section{Participants}

The study involved 198 subjects, 158 of whom comprised of the study group (79 females [F] and 79 males [M]). The average age was $41.4 \pm 3.5$ years (range: $20-44$ years of age). The study groups included SF+alexithymia (A)-M (25 participants), SF+A-F (25 participants), GAD+A-M (20 participants), GAD+A-F (20 participants), $\mathrm{PD}+\mathrm{A}-\mathrm{M}$ (17 participants), $\mathrm{PD}+\mathrm{A}-\mathrm{F}$ (17 participants), A-M (17 participants), and A-F (17 participants). Diagnostic and Statistical Manual of Mental Disorders, Fifth Edition criteria were utilized to diagnose $\mathrm{PD}, \mathrm{SF}$, and GAD. ${ }^{25}$ Patients enrolled in the study came to the Crisis Intervention Centre at the Department of Psychiatry in Bydgoszcz due to anxiety symptoms. Also, all of them had alexithymia and a history of recurrent urticaria.

Before admission, the subjects had started pharmacological treatment with the following medications: selective 
Table I Percentage of patients taking psychiatric medications before admission to the Department of Psychiatry

\begin{tabular}{llllll}
\hline $\begin{array}{l}\text { Percentage of patients } \\
\text { taking medications }\end{array}$ & $\begin{array}{l}\text { SSRI } \\
\text { (escitalopram) }\end{array}$ & $\begin{array}{l}\text { SNRI } \\
\text { (venlafaxine) }\end{array}$ & $\begin{array}{l}\text { NaSSA } \\
\text { (mirtazapine) }\end{array}$ & $\begin{array}{l}\text { NDRI } \\
\text { (bupropion) }\end{array}$ & $\begin{array}{l}\text { SARI } \\
\text { (trazodone) }\end{array}$ \\
\hline Females & 20 & 17 & 8 & 6 & 9 \\
Males & 23 & 12 & 6 & 7 & 11 \\
\hline
\end{tabular}

Abbreviations: SSRI, selective serotonin reuptake inhibitor; SNRI, serotonin-norepinephrine reuptake inhibitor; NaSSA, noradrenergic and specific serotonergic antidepressant; NDRI, norepinephrine-dopamine reuptake inhibitor; SARI, serotonin antagonist and reuptake inhibitor.

serotonin reuptake inhibitor (escitalopram), serotoninnorepinephrine reuptake inhibitor (venlafaxine), noradrenergic and specific serotonergic antidepressant (mirtazapine), norepinephrine-dopamine reuptake inhibitor (bupropion), serotonin antagonist and reuptake inhibitor (trazodone) (Table 1), and this took place between 2012 and 2015.

Following admission to the Department of Psychiatry, the treatment was discontinued since it was ineffective. One week after treatment discontinuation, prescreening of patients was performed in order to assign them to particular study groups.

Patients who met the entrance criteria were qualified for screening. Twenty-two percent of the prescreened patients who did not fulfill the entrance criteria were considered "screen-failures".

On examination, they had been experiencing a remission of urticaria for at least 1 year. The control group (C) involved 40 healthy subjects (20 females and 20 males) assigned according to sex and age. Individuals comprising the control group applied on their own initiative to the Department of Psychiatry in order to be enrolled in the study. They were qualified by the same psychiatry specialist. None of the test subjects were incapacitated, soldiers in compulsory military service, persons held in custody, persons in a reporting or other relationship, nor were they hospital employees. All of them had full legal capacity. The average age of the control group amounted to $40.8 \pm 3.1$ years (range: $20-43$ years of age). Exclusion criteria for both groups were established within the study and involved a diagnosis of mental illnesses other than indicated, organic damage to the central nervous system, detected alcohol or other psychoactive substance abuse, and treatment for infectious and chronic systemic diseases. Individuals with smoking habits and taking medications were also excluded from the study.

\section{Study scales}

\section{Toronto Alexithymia Scale}

The alexithymia construct was created by the psychiatrist Sifneos in 1972 and subsequently operationalized by Taylor et $\mathrm{al}^{26}$ as the Toronto Alexithymia Scale (TAS) along with its three subscales: difficulty describing feelings (DDF), difficulty identifying feelings (DIF), and externally oriented thinking (EOT). Currently, the TAS-20 is the most widely used self-report measure.

The DDF subscale comprises self-report items that determine the ability to cognitively express and describe feelings and emotions. The DIF subscale indicates the ability to internally distinguish and identify feelings and emotions. Finally, the EOT subscale consists of self-descriptions that refer to one's tendency to maintain external attention directed at material objects.

The maximum score for a shortened version of the TAS-20 is 100 . The subscale maximum scores are 25 (DDF), 35 (DIF), and 40 (EOT). The TAS-20 total score for alexithymic patients is 61 or more (Table 2$){ }^{26}$

\section{Hamilton Anxiety Rating Scale}

The Hamilton Anxiety Rating Scale (HAM-A) was one of the earliest established rating scales to measure the severity of anxiety symptoms. Since then, it has been commonly utilized in clinical and research settings. It is a 14 -item scale in which each item is specified by a series of symptoms. The HAM-A measures both psychic anxiety (mental agitation and psychological distress) and somatic anxiety (physical complaints connected with anxiety). Despite its general application in

Table 2 Proportion of subjects who had either alexithymia or alexithymia concurrent with anxiety disorders

\begin{tabular}{|c|c|c|c|c|}
\hline \multirow[t]{2}{*}{ Group } & \multicolumn{4}{|l|}{$M$} \\
\hline & $\mathbf{A}$ & $\mathbf{S F}+\mathbf{A}-\mathbf{M}$ & GAD+A-M & PD + A-M \\
\hline \multirow{3}{*}{$\begin{array}{l}\% \text { of TAS- } 20 \\
\text { total ( } \geq 6 \text { I points) }\end{array}$} & 10 & 10 & 20 & 23 \\
\hline & $\mathbf{F}$ & & & \\
\hline & $\bar{A}$ & $\mathbf{S F}+\mathbf{A}-\mathbf{F}$ & GAD+A-F & PD + A-F \\
\hline $\begin{array}{l}\% \text { of TAS- } 20 \text { total } \\
(\geq 6 \mid \text { points })\end{array}$ & 10 & 12 & 22 & 24 \\
\hline
\end{tabular}

Abbreviations: TAS-20, Toronto Alexithymia Scale; A-M, alexithymia males; A-F, alexithymia females; SF+A-M, social phobia + alexithymia males; SF $+A-F$, social phobia + alexithymia females; GAD+A-M, generalized anxiety disorder + alexithymia males; GAD+A-F, generalized anxiety disorder + alexithymia females; PD+A-M, panic disorder + alexithymia males; PD+A-F, panic disorder + alexithymia females; $M$, male; F, female; A, alexithymia. 
clinical trials, the scale is said to have some drawbacks related to poor ability to differentiate between anxiolytic and antidepressant effects and between somatic anxiety and somatic side effects. Also, no standardized probe questions are given by the HAM-A. However, levels of interrater reliability for the scale have been reported to be satisfactory.

Each item is scored on a $0-4$ scale, where 0 stands for "not present" and 4 for "severe". The total score ranges from 0 to 56 with $<17$ indicating mild severity, 18-24 mild-to-moderate severity, and 25-30 moderate-to-severe severity. ${ }^{27}$ The eligibility cutoff score for patients with GAD was 22 .

\section{Statistical analysis}

A number of quantitative traits were subject to a descriptive statistical analysis. The analysis was aimed at obtaining measures, such as the arithmetic mean (xsr), standard deviation (SD), and middle quartiles $\left(\mathrm{Q}_{2}=\mathrm{Me}\right)$.

The Shapiro-Wilk test was adopted to examine the normal distribution of variables. Regarding variables with normal distribution, the comparison of two mean values in the study groups was conducted by means of the Student's $t$-test, and it followed verification of homogeneity of variance with the Fisher-Snedecor test. Two groups of variables without normal distribution were contrasted by means of the Mann-Whitney $U$-test. The chi-square test was utilized to examine the significance of differences between the fractions and some dichotomous features. Therefore, for statistical hypotheses verification, parametric and nonparametric statistical tests were applied with a significance level of $P \leq 0.05 .^{28}$

In addition to the descriptive analysis, one- and multifactor analyses of variance were carried out.

\section{Ethics}

This study received approval of the Bioethics Committee of the Medical College in Bydgoszcz. All information about the research was given to each study participant who then provided written informed consent for enrollment. All the subjects included in the study were interviewed, and their mental status was evaluated by a psychiatry specialist, the first author of this paper.

\section{Results}

The first comparison regarded the control group and the group of patients with alexithymia (A-M, A-F). Statistically significant differences in the mean were found $(P<0.001)$. It was observed that in both cases of males and females, all diagnostic scales indicated a lower value of mean test results for the controls versus the group of patients with alexithymia (A). With regard to sex, greater differences were observed in males than females.

Females with alexithymia (A-F) were reported to have higher mean values on the TAS-20 scale and its subscales (DDF) versus males with alexithymia (A-M). With reference to the EOT and DIF subscales, as well as the HAM-A, similar mean values were revealed between males and females (Table 3; Figure 2).

A significance test for differences between the $\mathrm{A}$ and $\mathrm{PD}+\mathrm{A}$ groups revealed diverse results. The $\mathrm{PD}+\mathrm{A}$ group was reported to have a slightly higher score than the A group. This was observed for the TAS-20 $(P=0.008)$, DIF $(P=0.001)$, and EOT $(P=0.033)$. However, differences for the HAM-A and DDF were not statistically significant $(P>0.05)$.

Table 3 The mean scores for the scales in particular diagnostic tests

\begin{tabular}{|c|c|c|c|c|c|c|c|}
\hline \multirow[t]{3}{*}{ Measure } & \multicolumn{5}{|c|}{ Group } & \multirow{2}{*}{\multicolumn{2}{|c|}{$M$ vs $F$}} \\
\hline & \multicolumn{2}{|l|}{ C-M } & \multicolumn{3}{|l|}{ C-F } & & \\
\hline & Av & SD & $\mathrm{Me}$ & Av & SD & Me & $P$-value \\
\hline TAS-20 & 30.50 & 6.05 & 32.50 & 41.35 & 6.92 & 43.00 & 0.001 \\
\hline DDF & 9.55 & 3.30 & 9.50 & 10.15 & 3.57 & 9.00 & 0.642 \\
\hline DIF & 14.65 & 5.36 & 14.50 & 13.60 & 5.32 & 16.00 & 0.587 \\
\hline ЕОT & 12.45 & 2.95 & 12.00 & 18.15 & 4.22 & 17.00 & 0.001 \\
\hline \multirow[t]{2}{*}{ HAM-A } & 6.35 & 3.70 & 6.00 & 2.75 & 1.37 & 3.00 & 0.001 \\
\hline & \multicolumn{2}{|l|}{$A-M$} & \multicolumn{3}{|l|}{ A-F } & & \\
\hline TAS-20 & 61.71 & 1.90 & 61.00 & 65.12 & 2.55 & 65.00 & 0.001 \\
\hline DDF & 15.88 & 1.80 & 15.00 & 16.12 & 2.78 & 16.00 & 0.945 \\
\hline DIF & 22.65 & 2.64 & 22.00 & 20.18 & 5.28 & 19.00 & 0.023 \\
\hline EOT & 26.47 & 4.69 & 26.00 & 25.06 & 4.68 & 26.00 & 0.580 \\
\hline \multirow[t]{2}{*}{ HAM-A } & 23.53 & 6.58 & 19.00 & 19.76 & 1.86 & 19.00 & 0.540 \\
\hline & \multicolumn{2}{|c|}{$\mathbf{S F}+\mathbf{A}-\mathbf{M}$} & \multicolumn{3}{|c|}{$\mathbf{S F}+\mathbf{A}-\mathbf{F}$} & & \\
\hline TAS-20 & 84.80 & 7.79 & 86.00 & 79.08 & 8.53 & 78.00 & 0.011 \\
\hline DDF & 19.56 & 3.81 & 20.00 & 17.92 & 4.80 & 17.00 & 0.185 \\
\hline DIF & 30.28 & 3.63 & 30.00 & 28.32 & 5.00 & 28.00 & 0.177 \\
\hline ЕОT & 29.00 & 5.55 & 28.00 & 27.88 & 5.15 & 28.00 & 0.647 \\
\hline \multirow[t]{2}{*}{ HAM-A } & 21.00 & 2.22 & 21.00 & 20.88 & 2.37 & 21.00 & 0.716 \\
\hline & \multicolumn{2}{|c|}{ GAD+A-M } & \multicolumn{3}{|c|}{ GAD+A-F } & & \\
\hline TAS-20 & 70.20 & 9.23 & 69.00 & 78.00 & 13.23 & 80.50 & 0.074 \\
\hline DDF & 17.30 & 3.47 & 17.00 & 17.20 & 3.74 & 16.50 & 0.828 \\
\hline DIF & 25.10 & 6.32 & 26.50 & 23.90 & 7.24 & 21.50 & 0.797 \\
\hline EOT & 30.00 & 6.59 & 29.50 & 26.90 & 6.13 & 27.50 & 0.193 \\
\hline \multirow[t]{2}{*}{ HAM-A } & 27.45 & 3.36 & 27.00 & 29.85 & 2.89 & 30.50 & 0.025 \\
\hline & \multicolumn{2}{|c|}{ PD+A-M } & \multicolumn{2}{|c|}{ PD+A-F } & & & \\
\hline TAS-20 & 63.76 & 8.11 & 59.00 & 64.82 & 7.74 & 66.00 & 0.602 \\
\hline DDF & 12.47 & 4.64 & 13.00 & 10.35 & 4.47 & 8.00 & 0.319 \\
\hline DIF & 16.29 & 5.49 & 16.00 & 16.06 & 4.22 & 16.00 & $0.74 I$ \\
\hline EOT & 20.94 & 6.00 & 18.00 & 24.29 & 4.75 & 25.00 & 0.096 \\
\hline HAM-A & 21.35 & 3.14 & 21.00 & 20.53 & 3.06 & 21.00 & 0.424 \\
\hline
\end{tabular}

Abbreviations: TAS-20, Toronto Alexithymia Scale; DDF, difficulty describing feelings; DIF, difficulty identifying feelings; EOT, externally oriented thinking; HAM-A, Hamilton Anxiety Rating Scale; C-M, control group males; C-F, control group females; A-M, alexithymia males; A-F, alexithymia females; SF+A-M, social phobia + alexithymia males; SF+A-F, social phobia + alexithymia females; GAD+A-M, generalized anxiety disorder + alexithymia males; GAD+A-F, generalized anxiety disorder + alexithymia females; PD+A-M, panic disorder + alexithymia males; PD+A-F, panic disorder + alexithymia females; Av, average; SD, standard deviation; Me, median; $M$, male; F, female. 


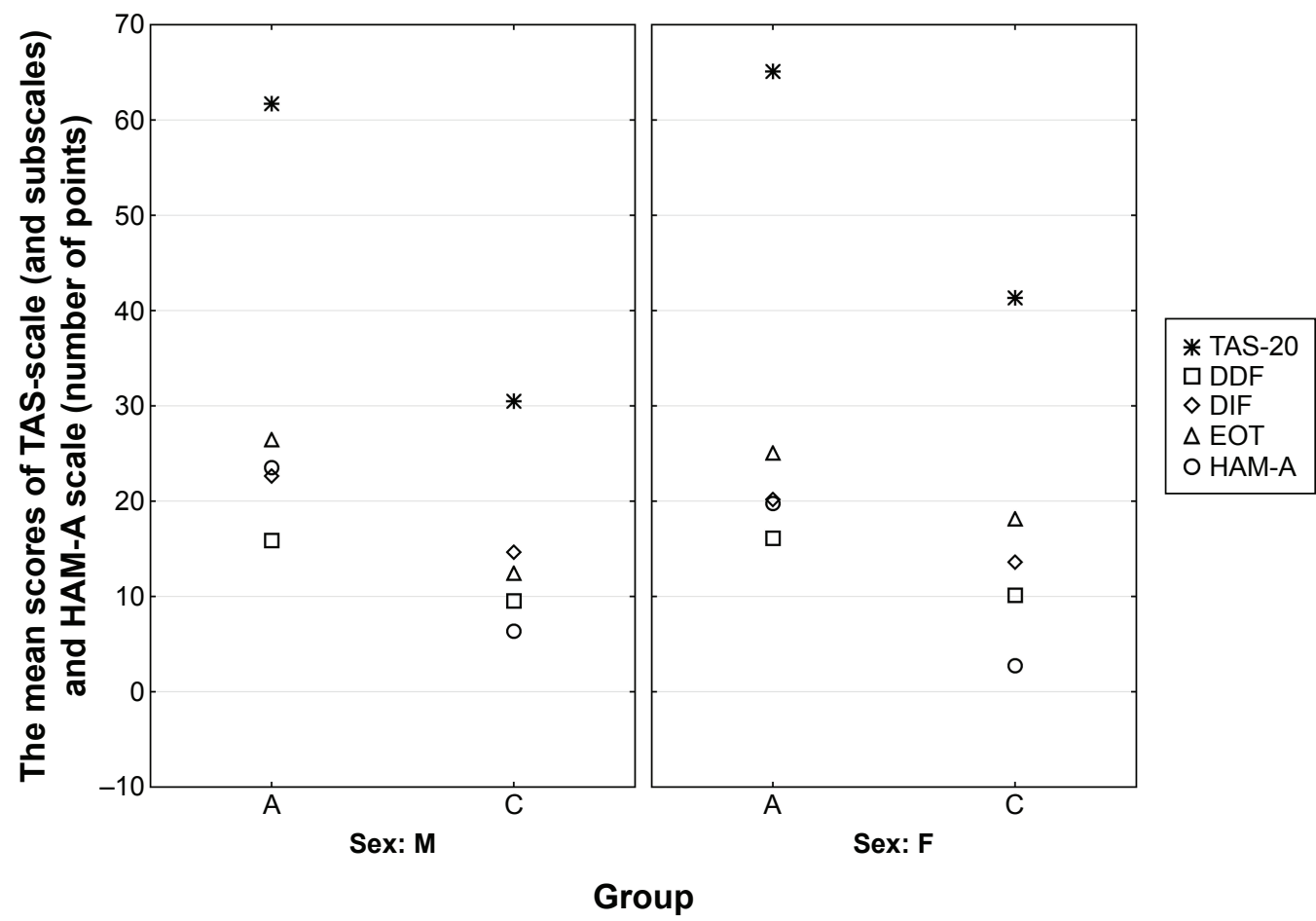

Figure 2 The mean result of diagnostic tests for females and males with alexithymia and for the control group. Abbreviations: TAS-20, Toronto Alexithymia Scale; DDF, difficulty describing feelings; DIF, difficulty identifying feelings; EOT, externally oriented thinking; HAM-A, Hamilton Anxiety Rating Scale; A, alexithymia; C, control group; M, male; F, female.

Differences in the mean results between males and females with $\mathrm{PD}+\mathrm{A}$ were also interesting. The differences for all the studied parameters (TAS-20, DDF, DIF, EOT, and HAM-A) were insignificant. However, when comparing the results between $\mathrm{A}$ and $\mathrm{PD}+\mathrm{A}$ groups among males and females, a different observation was made (Table 3; Figure 3). For females, significant differences between $\mathrm{A}$ and $\mathrm{PD}+\mathrm{A}$ groups were reported only on the DDF subscale $(P<0.001)$. For males, significant differences were found on the DDF $(P=0.040)$, DIF $(P<0.001)$, and EOT $(P=0.016)$ subscales.

In the case of contrasting patients with alexithymia (A) with subjects suffering from $\mathrm{SF}+\mathrm{A}$, the differences in the mean were statistically significant for the TAS-20 test $(P<0.001)$. The differences in the mean on the three subscales of the TAS-20 scale (DDF, DIF, EOT) revealed statistical significance as well.

It was only the HAM-A scale, for which the MannWhitney $U$-test showed insignificant differences in the mean values $(P=0.261)$.

Males with SF concomitant with alexithymia (SF+A-M) were reported to have higher mean values on the TAS-20 scale and its subscales (DDF, DIF) when compared to females.

Comparable mean results in the group of males and females with $\mathrm{SF}+\mathrm{A}$ were found on the EOT subscale (Table 3; Figure 4).
Having compared patients with alexithymia (A) with subjects suffering from GAD+A, statistical significance was revealed with regard to the differences in the mean $(P<0.001)$ on the TAS-20 scale and its EOT subscale as well as on the HAM-A $(P<0.05)$. It was only the subscales DDF ( $P=0.141)$ and $\operatorname{DIF}(P=0.053)$, for which the Mann-Whitney test showed insignificant differences in the mean values.

Nevertheless, since the significance level of the difference observed on the DIF subscale is close enough to the accepted threshold of $P=0.05$, its result should be considered nearly significant.

Both males and females with GAD concomitant with alexithymia (GAD+A) were reported to have higher mean values on the TAS-20 scale and its EOT subscale, as well as on the HAM-A scale when compared to the control group (Table 3; Figure 5).

In addition to the earlier analyses, single- and multifactor analyses of variance were conducted. Statistically significant differences were revealed in all study groups for all performed tests. It was found that sex was a significant factor responsible for these differences only in the case of the TAS-20 scale, the DIF subscale, and the HAM-A scale (Table 4).

Two-factor analysis of variance included groups assigned according to both the type of disorder and sex. Statistically significant differences between the groups were revealed 


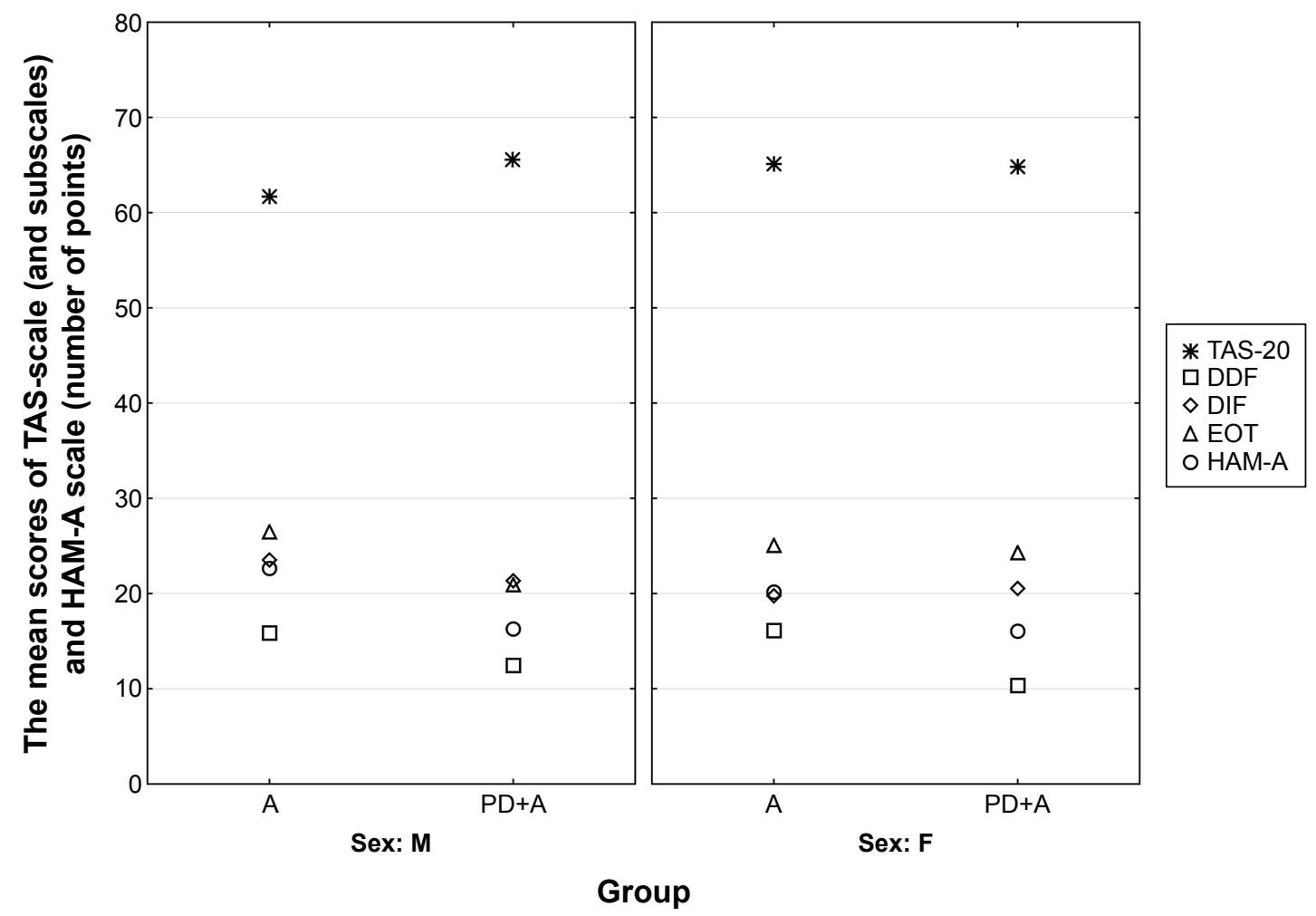

Figure 3 The mean result of diagnostic tests for females and males with alexithymia, as well as alexithymia concurrent with panic disorder.

Abbreviations: TAS-20, Toronto Alexithymia Scale; DDF, difficulty describing feelings; DIF, difficulty identifying feelings; EOT, externally oriented thinking; HAM-A, Hamilton Anxiety Rating Scale; A, alexithymia; PD+A, panic disorder + alexithymia; M, male; F, female.

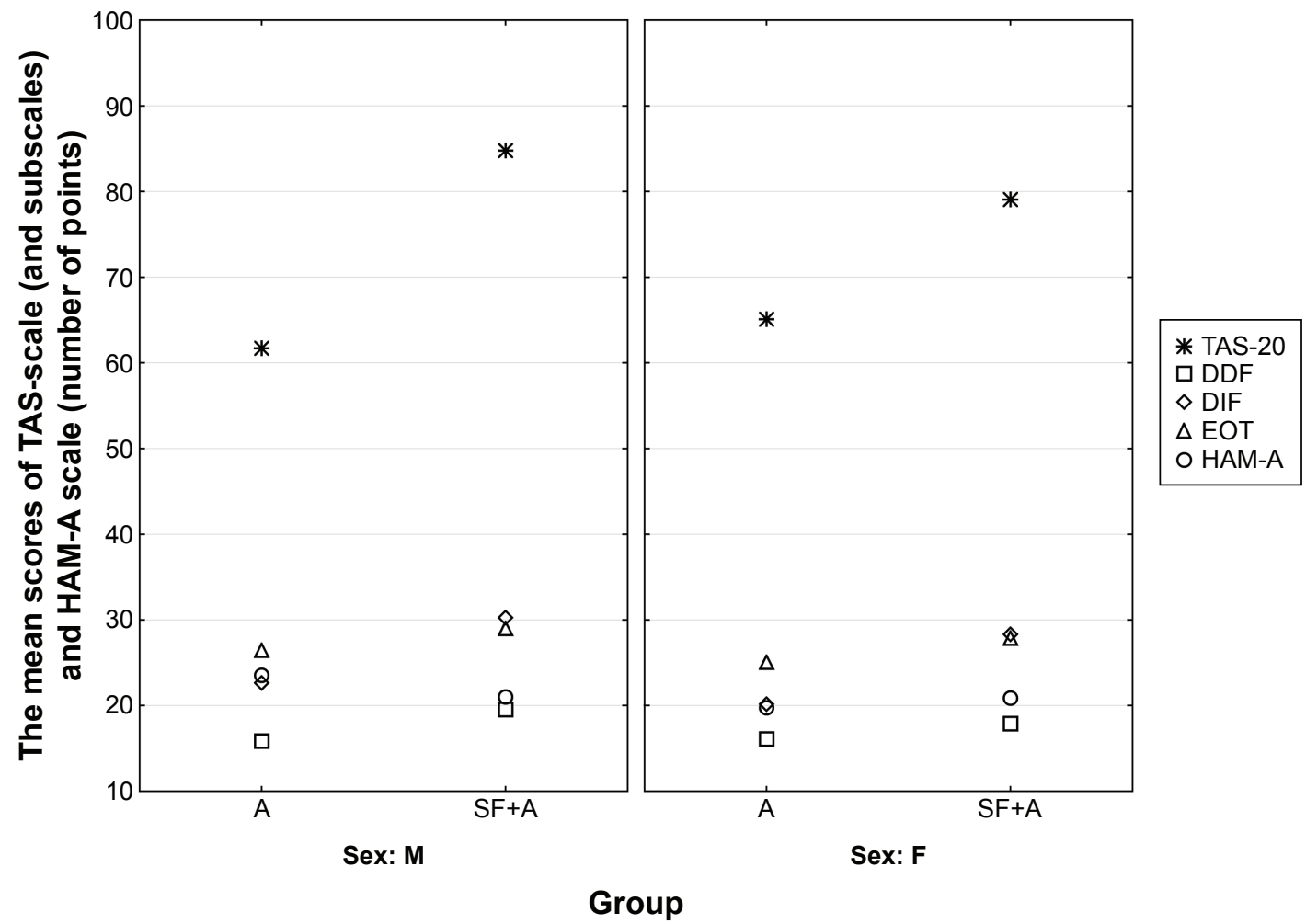

Figure 4 The mean result of diagnostic tests for females and males with alexithymia, as well as alexithymia concurrent with social phobia.

Abbreviations: TAS-20, Toronto Alexithymia Scale; DDF, difficulty describing feelings; DIF, difficulty identifying feelings; EOT, externally oriented thinking; HAM-A, Hamilton Anxiety Rating Scale; A, alexithymia; SF+A, social phobia + alexithymia; M, male; F, female. 


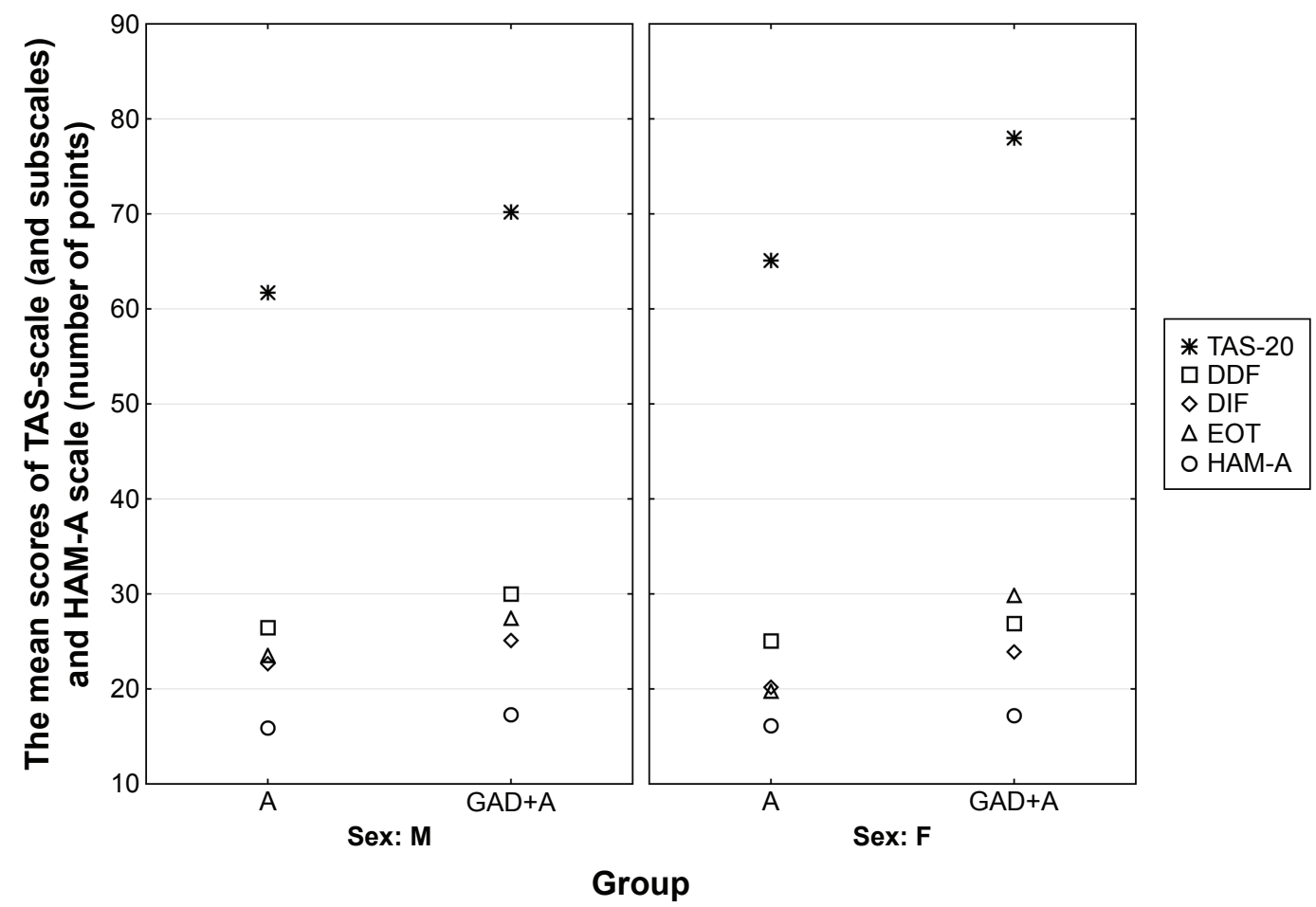

Figure 5 The mean result of diagnostic tests for females and males with alexithymia, as well as alexithymia concurrent with generalized anxiety disorder. Abbreviations: TAS-20, Toronto Alexithymia Scale; DDF, difficulty describing feelings; DIF, difficulty identifying feelings; EOT, externally oriented thinking; HAM-A, Hamilton Anxiety Rating Scale; A, alexithymia; GAD+A, generalized anxiety disorder + alexithymia; M, male; F, female.

for the TAS-20 scale and its EOT subscale, as well as for the HAM-A scale. However, the differences between these groups for the DDF and DIF subscales were reported to be insignificant.

\section{Discussion}

CIU, commonly referred to as the occurrence of extensive itchy wheals lasting at least 6 weeks, belongs to significant diseases among other dermatoses that are said to be related to psychological factors. For the etiology of the disease to be defined, it may be important to closely consider the inability to express or elaborate emotions. ${ }^{21,29}$ It has been proved that CIU is caused by personality-based difficulties relating to emotional regulation with an emphasis on the feeling of anxiety. ${ }^{30}$ This deficit may be the reason for manifesting the

Table 4 ANOVA for the TAS-20 (DDF, DIF, EOT) and for the HAM-A

\begin{tabular}{llllll}
\hline ANOVA & TAS-20 & DDF & DIF & EOT & HAM-A \\
\hline Intercept & 0.001 & 0.001 & 0.001 & 0.001 & 0.001 \\
Group & 0.001 & 0.001 & 0.001 & 0.001 & 0.001 \\
Sex & 0.002 & 0.988 & 0.045 & 0.360 & 0.012 \\
Group*sex & 0.001 & 0.444 & 0.929 & 0.001 & 0.001
\end{tabular}

Abbreviations: ANOVA, analysis of variance; TAS-20, Toronto Alexithymia Scale; DDF, difficulty describing feelings; DIF, difficulty identifying feelings; EOT, externally oriented thinking; HAM-A, Hamilton Anxiety Rating Scale. experienced emotions through bodily symptoms, such as pruritus, angioedema, and urticarial vasculitis. ${ }^{31,32}$

In this paper, the authors present the study results of individuals with a history of $\mathrm{CIU}$, who additionally reported the symptoms of alexithymia or alexithymia concomitant with GAD, PD, or SF.

The obtained results indicate the presence of statistically significant differences in the mean $(P<0.0001)$ when comparing the $\mathrm{C}$ and $\mathrm{A}$ groups on the TAS-20 and HAM-A scales. This is reflected by higher values on the TAS-20 scale and its subscales (DDF, DIF) versus the female group. However, the anxiety level measured by the HAM-A scale was comparable in these groups. Having contrasted the groups with $\mathrm{SF}+\mathrm{A}$ and $\mathrm{A}$, statistically significant differences in the mean were observed both on the TAS-20 scale and all its subscales. Also, alexithymia in the male group with $\mathrm{SF}+\mathrm{A}$ showed higher values on the TAS-20 scale and its subscales (DDF, DIF) than in the female group. The anxiety level measured by the HAM-A was statistically insignificant in these contrasted groups. Having compared the groups with GAD+A and A, statistically significant differences in the mean were observed both on the TAS-20 scale and its EOT subscale, as well as on the HAM-A scale. The highest level of alexithymia was observed in females from the GAD+A group on the TAS-20 scale and its EOT subscale. The most substantial anxiety level 
measured by the HAM-A was detected in females from the GAD+A group.

The obtained results prove that males suffering from alexithymia concomitant with SF (SF+A-M) and females with alexithymia concomitant with GAD (GAD+A-F) were reported to have more elevated levels of alexithymia on the TAS-20 scale. In the case of males comprising the SF+A group, alexithymia presented more strongly with DIF and DDF. In turn, in the case of females from the SF+A group, alexithymia exerted the greatest influence on the operational thinking style (EOT), and it disturbed cognitive functions. Individuals suffering from alexithymia without concomitant anxiety disorders, such as SF, GAD, and PD, had alexithymia with more substantial values on the TAS-20 scale and its subscales (DDF, DIF) with regard to males versus females. However, the anxiety level in this group (A) measured by the HAM-A scale was comparable between male and female groups.

The previously conducted studies on alexithymia with regard to anxiety disorders failed to involve patients with other concurrent diseases, for example, idiopathic urticaria. They focused on patients with alexithymia and anxiety disorders. ${ }^{33,34}$ Thus, the study results presented in this article are considered pioneering by the authors.

Cucchi et $\mathrm{al}^{35}$ claimed that patients with PDs revealed a higher level of alexithymia than healthy individuals. The study by Dalbudak et $\mathrm{al}^{3}$ showed exacerbation of alexithymia on the TAS-20 general scale and its DDF subscale in students with an elevated anxiety level and diagnosed SF. Moreover, Koyuncu et $\mathrm{al}^{36}$ claimed that $32.9 \%$ of patients with SF suffered from alexithymia. Additionally, individuals suffering from SF were more predisposed to developing depression. In patients with depression and concomitant $\mathrm{SF}$, the alexithymia level was higher than in subjects with SF alone. ${ }^{37}$ Also, alexithymia disturbed social functioning in this group of subjects, as well as being responsible for secondary exacerbation of SF ${ }^{4}$ Therefore, the results of this study indicate that concomitance of two psychiatric disorders (SF and depression) makes alexithymia more severe. What is more, De Berardis et $\mathrm{al}^{38}$ observed that individuals with GAD and alexithymia expressed by an increased DIF subscale frequently had suicidal thoughts.

Majohr et $\mathrm{al}^{39}$ found that there exists a relationship between alexithymia and anxiety-based dissocial personality disorders. The authors concluded that alexithymia and dissocial personality disorders may predispose an individual to panic attacks. In patients with dissocial personality disorders, alexithymia manifested as "DIF". Patients who were observed to have the symptoms of dissocial personality disorders were reported to have an increased level of alexithymia, particularly represented on the subscales of the TAS-20 scale, which involved DIF and, to a lesser extent, "DDF". The results of the study confirm a strong relationship between alexithymia and dissocial personality disorders in patients with PD. ${ }^{40}$

Very few studies have been found in the literature on the presence of alexithymia in patients with past CIU.41,42

The study by Zachariae et al revealed that patients suffering from urticaria and posttraumatic stress disorder (PTSD) were observed with higher alexithymia levels than the controls. Their defense mechanism was classified as defensive, and it involved conscious self-image management along with elevated manifest anxiety. ${ }^{43}$

Another study by Conrad et $\mathrm{al}^{30}$ found that there exists a relationship between intensified itch in patients with CIU and a tendency to suppress negative emotions, such as anger. Moreover, these authors also marked the relationship between exacerbation of depression and exacerbation of itch in psoriasis. ${ }^{30}$

These studies also indicate a possibly higher dysregulation of the hypothalamic-pituitary-adrenal axis taking part in the neurohormonal response with respect to anxiousdepressive disorders. The axis is also responsible for exacerbation or recurrence of symptoms related to many somatic diseases, including dermatological conditions, such as CIU, the pathogenesis of which is linked to immune and neurohormonal factors. ${ }^{44}$

On the basis of the studies conducted by the authors of this paper, it was revealed that GAD and SF exacerbate alexithymia symptoms in patients with past CIU and with $\mathrm{GAD}+\mathrm{A}$ and $\mathrm{SF}+\mathrm{A}$. PDs do not exacerbate alexithymia in patients experiencing remission of CIU or in subjects with $\mathrm{PD}+\mathrm{A}$. The studies proved the need for psychotherapeutic treatment directed toward overcoming difficulties with expressing feelings in patients from GAD and SF groups and with concomitant alexithymia. Moreover, in the group of patients with GAD+A, it is crucial to provide psychotherapeutic and/or pharmacological treatment aimed at reducing anxiety severity and to treat anxiety disorders, taking into account psychological factors. Psychotherapeutic and/or pharmacological treatment for anxiety disorders and alexithymia in patients with past CIU may prevent recurrence of urticaria. $^{45}$

\section{Conclusion}

Anxiety disorder, SF, and GAD are factors that exacerbate alexithymia symptoms in patients with a history of CIU. 


\section{Limitations}

The study groups were composed of patients with a history of recurrent urticaria; yet, they were experiencing a remission of the disease at the time of enrollment. Therefore, urticaria severity was not evaluated by means of the Urticaria Severity Score. Moreover, when assigning patients to particular groups according to the type of disorder, the authors did not include patients with PTSD since it was impossible to select subjects with the same duration of PTSD symptoms.

\section{Acknowledgments}

The paper was proofread by a native speaker and approved. This study was not funded by grants from any funding agency, either public, commercial, or nonprofit.

\section{Disclosure}

The authors report no conflicts of interest in this work.

\section{References}

1. Fava GA. Psychotherapy and psychosomatics: a tribute to Peter E. Sifneos, MD (1920-2008). Psychother Psychosom. 2009;78(6):328-329.

2. Demers LA, Koven NS. The relation of alexithymic traits to affective theory of mind. Am J Psychol. 2015;128(1):31-42.

3. Dalbudak E, Evren C, Aldemir S, Coskun KS, Yildırım FG, Ugurlu H. Alexithymia and personality in relation to social anxiety among university students. Psychiatry Res. 2013;209(2):167-172.

4. Ertekin E, Koyuncu A, Ertekin BA, Özyildirim İ. Alexithymia in social anxiety disorder: is there a specific relationship or is it a feature of comorbid major depression? Anadolu Psikiyatri Dergisi. 2015;16(2): 130-137.

5. Teymoori S, Sanagooe Moharer GR. Examination of relationship between social anxiety and alexithymia in students of Islamic Azad University of zahedan branch. Int J Rev Life Sci. 2014;4(12):65-69.

6. Keefer KV, Taylor GJ, Parker JD, Inslegers R, Michael Bagby R. Measurement equivalence of the Toronto Structured Interview for Alexithymia across language, gender, and clinical status. Psychiatry Res. 2015;228(3):760-764.

7. Myers LB, Derakshan N. The relationship between two types of impaired emotion processing: repressive coping and alexithymia. Front Psychol. 2015;6:809.

8. Spitzer C, Siebel-Jurges U, Barnow S, Grabe HJ, Freyberger HJ. Alexithymia and interpersonal problems. Psychother Psychosom. 2005; 74(4):240-246.

9. Willemsen R, Roseeuw D, Vanderlinden J. Alexithymia and dermatology: the state of the art. Int J Dermatol. 2008;47(9):903-910.

10. Hunkin V, Chung MC. Chronic idiopathic urticaria, psychological co-morbidity and posttraumatic stress: the impact of alexithymia and repression. Psychiatr Q. 2012;83(4):431-447.

11. Barbosa F, Freitas J, Barbosa A. Chronic idiopathic urticaria and anxiety symptoms. J Health Psychol. 2011;16(7):1038-1047.

12. Li S, Zhang B, Guo Y, Zhang J. The association between alexithymia as assessed by the 20-item Toronto Alexithymia Scale and depression: a meta-analysis. Psychiatry Res. 2015;227(1):1-9.

13. De Berardis D, Conti C, Iasevoli F, et al. Alexithymia and its relationships with acute phase proteins and cytokine release: an updated review. J Biol Regul Homeost Agents. 2014;28(4):795-799.

14. Koh KB, Choe E, Song JE, Lee EH. Effect of coping on endocrinoimmune functions in different stress situations. Psychiatry Res. 2006; 143(2-3):223-234.
15. Ogłodek E, Szota A, Just M, Moś D, Araszkiewicz A. The role of the neuroendocrine and immune systems in the pathogenesis of depression. Pharmacol Rep. 2014;66(5):776-781.

16. Ihme K, Sacher J, Lichev V, et al. Alexithymic features and the labeling of brief emotional facial expressions - an fMRI study. Neuropsychologia. 2014;64C:289-299.

17. Onoda K, Yamaguchi S. Dissociative contributions of the anterior cingulate cortex to apathy and depression: topological evidence from resting-state functional MRI. Neuropsychologia. 2015;77:10-18.

18. Mula M, Pini S, Cassano GB. The neurobiology and clinical significance of depersonalization in mood and anxiety disorders: a critical reappraisal. $J$ Affect Disord. 2007;99(1-3):91-99.

19. Ogłodek EA, Szota AM, Just MJ, Moś DM4, Araszkiewicz A. The MCP-1, CCL-5 and SDF-1 chemokines as pro-inflammatory markers in generalized anxiety disorder and personality disorders. Pharmacol Rep. 2015;67(1):85-89.

20. Ogłodek E, Moś D, Araszkiewicz A. Burnout as a consequence of chronic stress in the patients suffering from dermatological diseases. Pol Merkur Lekarski. 2009;27(161):427-431.

21. Maniaci G, Epifanio MS, Marino MA, Amoroso S. The presence of alexithymia investigated by the TAS-20 in chronic urticaria patients: a preliminary report. Eur Ann Allergy Clin Immunol. 2006;38(1): $15-19$.

22. Rodriguez-Vallecillo E, Woodbury-Fariña MA. Dermatological manifestations of stress in normal and psychiatric populations. Psychiatr Clin North Am. 2014;37(4):625-651.

23. Chen Y, Lyga J. Brain-skin connection: stress, inflammation and skin aging. Inflamm Allergy Drug Targets. 2014;13(3):177-190.

24. Lugović-Mihić L, Ljubesić L, Mihić J, Vuković-Cvetković V, Troskot N, Situm M. Psychoneuroimmunologic aspects of skin diseases. Acta Clin Croat. 2013;52(3):337-345.

25. Price M, van Stolk-Cooke K. Examination of the interrelations between the factors of PTSD, major depression, and generalized anxietydisorder in a heterogeneous trauma-exposed sample using DSM 5 criteria. $J$ Affect Disord. 2015;186:149-155.

26. Taylor GJ, Bagby RM, Parker JD. Validation of the alexithymia construct: a measurement based approach. Can J Psychiatry. 1990;35(4): 290-297.

27. White D, Tavakoli S. Repetitive transcranial magnetic stimulation for treatment of major depressive disorder with comorbid generalized anxiety disorder. Ann Clin Psychiatry. 2015;27(3):192-196.

28. Campbell MJ, Machin D, Walters SJ. Medical Statistics. 4th ed. England: Willey-Blackwell; 2007.

29. Barbosa F, Freitas J, Barbosa A. Alexithymia in chronic urticaria patients. Psychol Health Med. 2011;16(2):215-224.

30. Conrad R, Geiser F, Haidl G, Hutmacher M, Liedtke R, Wermter F. Relationship between anger and pruritus perception in patients with chronic idiopathic urticaria and psoriasis. J Eur Acad Dermatol Venereol. 2008;22(9):1062-1069.

31. Jongen S, Axmacher N, Kremers NA, et al. An investigation of facial emotion recognition impairments in alexithymia and its neural correlates. Behav Brain Res. 2014;271:129-139.

32. Onur E, Alkin T, Sheridan MJ, Wise TN. Alexithymia and emotional intelligence in patients with panic disorder, generalized anxiety disorder and major depressive disorder. Psychiatr Q. 2013;84(3): 303-311.

33. Watson D, Naragon-Gainey K. Personality, emotions, and the emotional disorders. Clin Psychol Sci. 2014;2(4):422-442.

34. Izci F, Gültekin BK, Saglam S, Koc MI, Zincir SB, Atmaca M. Temperament, character traits, and alexithymia in patients with panic disorder. Neuropsychiatr Dis Treat. 2014;10:879-885.

35. Cucchi M, Cavadini D, Bottelli V, et al. Alexithymia and anxiety sensitivity in populations at high risk for panic disorder. Compr Psychiatry. 2012;53(6):868-874.

36. Koyuncu A, Ertekin E, Deveci E, et al. Age of onset in social anxiety disorder: relation to clinical variables and major depression comorbidity Ann Clin Psychiatry. 2015;27(2):848-849. 
37. Kim JH, Lee SJ, Rim HD, Kim HW, Bae GY, Chang SM. The relationship between alexithymia and general symptoms of patients with depressive disorders. Psychiatry Investig. 2008;5(3):179-185.

38. De Berardis D, Serroni N, Campanella D, et al. Alexithymia, suicide ideation, C-reactive protein and serum lipid levels among outpatients with generalized anxiety disorder. Arch Suicide Res. 2015;2:1-37.

39. Majohr KL, Leenen K, Grabe HJ, Jenewein J, Nuñez DG, Rufer M. Alexithymia and its relationship to dissociation in patients with panic disorder. J Nerv Ment Dis. 2011;199(10):773-777.

40. Galderisi S, Mancuso F, Mucci A, Garramone S, Zamboli R, Maj M. Alexithymia and cognitive dysfunctions in patients with panic disorder. Psychother Psychosom. 2008;77(3):182-188.

41. Kalkan G, Seçkin HY, Duygu F, Akbaş A, Ozyurt H, Sahin M. Oxidative stress status in patients with acute urticaria. Cutan Ocul Toxicol. 2014;33(2):109-114.
42. Sagdic A, Sener O, Bulucu F, et al. Oxidative stress status in patients with chronic idiopathic urticaria. Allergol Immunopathol (Madr). 2011;39(3): $150-153$.

43. Zachariae R, Lei U, Haedersdal M, Zachariae C. Itch severity and quality of life in patients with pruritus: preliminary validity of a Danish adaptation of the itch severity scale. Acta Derm Venereol. 2012;92(5):508-514.

44. Krupa Shankar DS, Ramnane M, Rajouria EA. Etiological approach to chronic urticaria. Indian J Dermatol. 2010;55(1):33-38.

45. Gregoriou S, Rigopoulos D, Katsambas A, et al. Etiologic aspects and prognostic factors of patients with chronic urticaria: nonrandomized, prospective, descriptive study. J Cutan Med Surg. 2009;13(4):198-203.

\section{Publish your work in this journal}

Neuropsychiatric Disease and Treatment is an international, peerreviewed journal of clinical therapeutics and pharmacology focusing on concise rapid reporting of clinical or pre-clinical studies on a range of neuropsychiatric and neurological disorders. This journal is indexed on PubMed Central, the 'PsycINFO' database and CAS, and is the official journal of The International Neuropsychiatric Association (INA). The manuscript management system is completely online and includes a very quick and fair peer-review system, which is all easy to use. Visit http://www.dovepress.com/testimonials.php to read real quotes from published authors.

\footnotetext{
Submit your manuscript here: http://www.dovepress.com/neuropsychiatric-disease-and-treatment-journal
} 